\title{
The main indicators of choosing the scheme of providing hot water supply in cities
}

\author{
$F$ Gazizov* and I.Ahmetova \\ Kazan State Power Engineering University, Kazan, Russia
}

\begin{abstract}
In the article the basic indicators defining the choice of this or that scheme of the organization of the closed hot water supply of the cities (further - HWS) using open schemes of HWS are considered. Block diagrams of boundary conditions and independent variables are presented. A pyramid of conditions affecting the level of capital and annual costs for the maintenance of heat supply systems for the useful life (25 years) of the equipment is proposed. The main provisions of the method and the program of choosing the most appropriate scheme of transition to the closed circuit of preparation of hot water with the calculation of weight coefficients are formulated.
\end{abstract}

\section{Prerequisites}

Paragraph 9 of the article 29 of FL-190 for the heat supplying organizations and bodies of local selfgovernment enshrined the obligation on transfer of the subscribers connected to the hot water at open circuit to a closed circuit hot water $[1,2]$. The relevance of the task to determine the main indicators when choosing the method of transfer to the closed circuit of the HWS is due to the fact that more than half of the existing heat supply systems in the Russian Federation are open [3 $6]$.

Due to the lack of approved methods of integrated assessment of scenarios for the transfer to the closed circuit HWS on the scale of urban settlements, uniformity in approach to the task of comparing scenarios and assessing the cost of activities for the organization of a closed circuit HWS can be achieved by feasibility study of each scenario for a single city.

In practice, local governments are not able to start working on the issue for a number of objective reasons, including as a result of insufficient funding and, as a consequence, the lack of the possibility of finding a reasonable solution in the development/annual updating of heat supply schemes.

Even if the feasibility study of the choice of transition to a closed circuit GVS, the final benchmark in the selection of the most appropriate option - is the total capital expenditure. This approach reflects the short-term minimum investment, without regard for the future.

\section{The formation of the main factors when choosing a script translation on a closed hot water system}

For the analysis of perspective scenarios of transition to the closed hot water system it is necessary to estimate the main indicators influencing the choice of each of possible solutions [7].

The list of the main indicators given in table 1 at an assessment of scenarios of transfer to the closed hot water system in the real project can be changed proceeding from features of the heat supply system considered separately.

According to the proposed main indicators, it is advisable to divide the proposed criteria into two categories:

- boundary conditions (by the type of logical variables "true/false»);

- independent variables (the value of which will vary from project to project and be converted into cash or in kind).

\section{Drawing up a flowchart of boundary conditions and independent variables}

The main indicators of the boundary conditions considered in the table. 1 are positions 2,3 and 6. Fig 1.

Key indicators 1, 4, 5, 7 presented in table 1 have a quantitative assessment (ton of conventional fuel, $\mathrm{kWh}$, RUB) and are considered as independent variables.

The primary difference between the main indicators of independent variables from the main indicators of boundary conditions is the presence of natural and, as a consequence, monetary equivalent. The monetary equivalent allows to estimate numerically influence of

*Corresponding author: fara_gazizov@inbox.ru 
Table 1. The main criteria for selecting a translation option on the closed hot water system key indicators influencing the choice.

\begin{tabular}{|l|l|l|}
\hline № & \multicolumn{1}{|c|}{ Основные показатели } & \multicolumn{1}{|c|}{ Примечание } \\
\hline 1 & $\begin{array}{l}\text { Degree-day of the heating period (DDHP) - heat } \\
\text { losses from the surface of the pipeline/ hydraulic } \\
\text { losses in the pipelines }\end{array}$ & $\begin{array}{l}\text { Four-pipe system in comparison with two-pipe has a large } \\
\text { total length of heat pipelines. }\end{array}$ \\
\hline 2 & $\begin{array}{l}\text { Availability of space for additional equipment at } \\
\text { the consumer - the size of the basement of } \\
\text { residential buildings. }\end{array}$ & $\begin{array}{l}\text { In case of lack of free space or inability to access it, } \\
\text { installation of IHP is not possible. }\end{array}$ \\
\hline 3 & $\begin{array}{l}\text { The capacity of the mains cold water supply } \\
\text { (CWS) - hydraulic losses in the pipelines. }\end{array}$ & $\begin{array}{l}\text { The transition to IHP/CHU options significantly increases } \\
\text { the load on the CWS. In this case, CWS will either need a } \\
\text { separate branch with cold water, or getting appropriate } \\
\text { connectivity option for four-pipe systems. }\end{array}$ \\
\hline 4 & $\begin{array}{l}\text { The presence of a cut-off for hot water at the } \\
\text { temperature graph - temperature graph of } \\
\text { thermal pipeline. }\end{array}$ & $\begin{array}{l}\text { An additional factor of transition to the four-pipe system, } \\
\text { where the temperature cutting can be abandoned. }\end{array}$ \\
\hline 5 & $\begin{array}{l}\text { The real heat load of the district - the presence } \\
\text { or absence of reserve capacity of the heat } \\
\text { pipeline }\end{array}$ & $\begin{array}{l}\text { Increased pipeline water consumption for options with } \\
\text { CHU/IHP compared to the four-pipe system and, as a } \\
\text { consequence, the need for new pipelines. }\end{array}$ \\
\hline 6 & $\begin{array}{l}\text { Type of soil and the possibility of work - the } \\
\text { density of urban development, improvement of } \\
\text { the area, access to communications, etc. }\end{array}$ & $\begin{array}{l}\text { The cost of laying pipelines depends on the complexity of } \\
\text { construction and installation works. }\end{array}$ \\
\hline 7 & $\begin{array}{l}\text { Operating costs - service life of pipelines and } \\
\text { main equipment. }\end{array}$ & $\begin{array}{l}\text { The four-pipe system, unlike the CHU/IHP, does not } \\
\text { require regular technical inspection and replacement of } \\
\text { the main equipment. }\end{array}$ \\
\hline
\end{tabular}

each of the main indicators of independent variables on the choice of the priority scheme of HWS of the considered territorial unit. Separately, it should be noted in this flowchart the division of costs for capital investments and annual costs. Such differentiation is extremely relevant when comparing thermal and hydraulic losses, as well as the cost of repairs and replacement of the main equipment. Summing up all economic indicators for the life cycle of the equipment will allow to perform a more objective assessment of the options of CHU/IHP and four-pipe system, because it takes into account the nominal life of the pipeline and heat exchange equipment. In addition, the stated period will include major repairs and replacement of heat exchange equipment for solutions with the installation of heat points on the type of CHU/IHP.

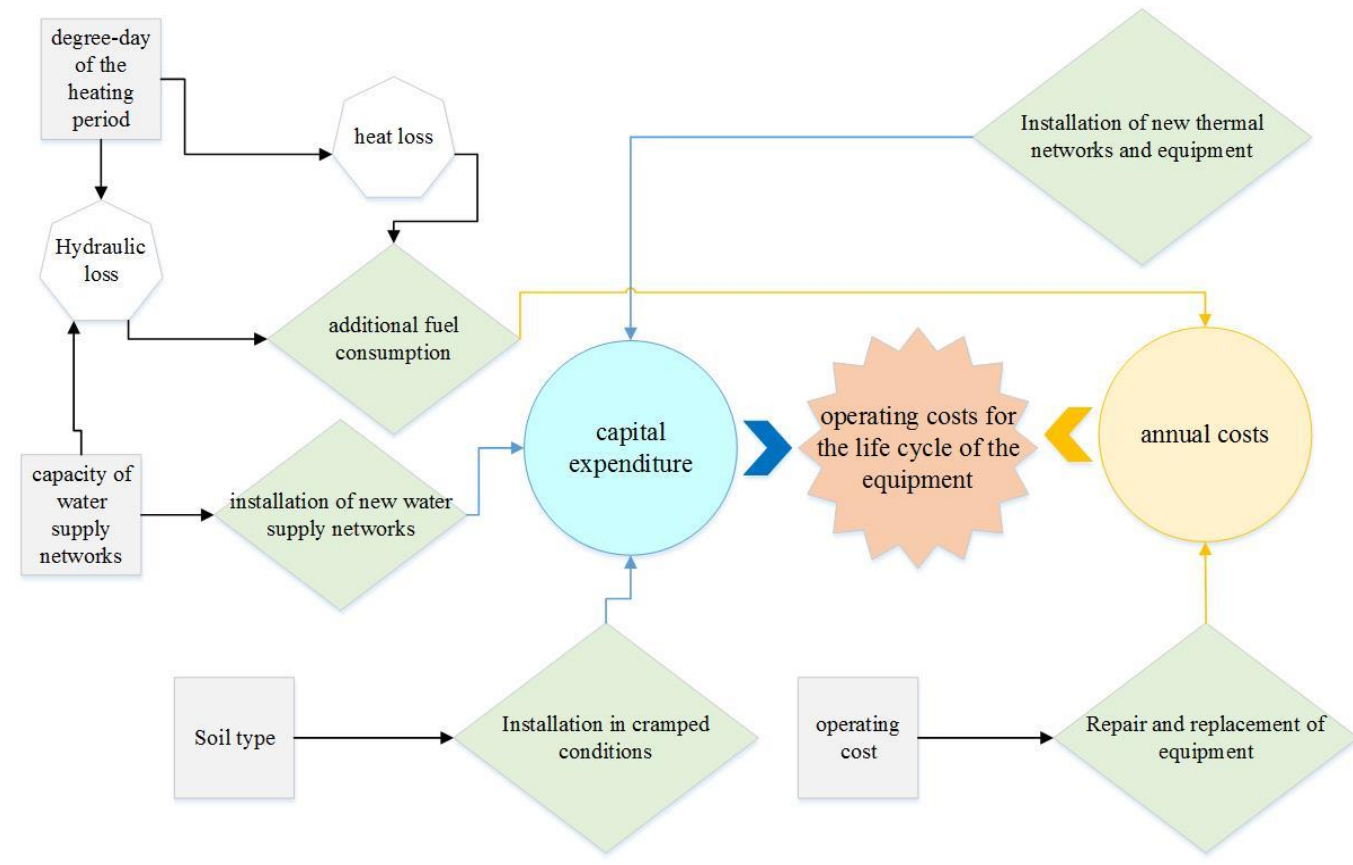

Fig. 1. Flowchart of independent variables. 
Thus, it becomes possible to display an enlarged block diagram of the evaluation of scenarios for the transfer to a closed DHW system, including the main indicators from Fig. 1. Below there is the proposed baseline calculation scheme within the framework of the developed methodology (Fig. 2).

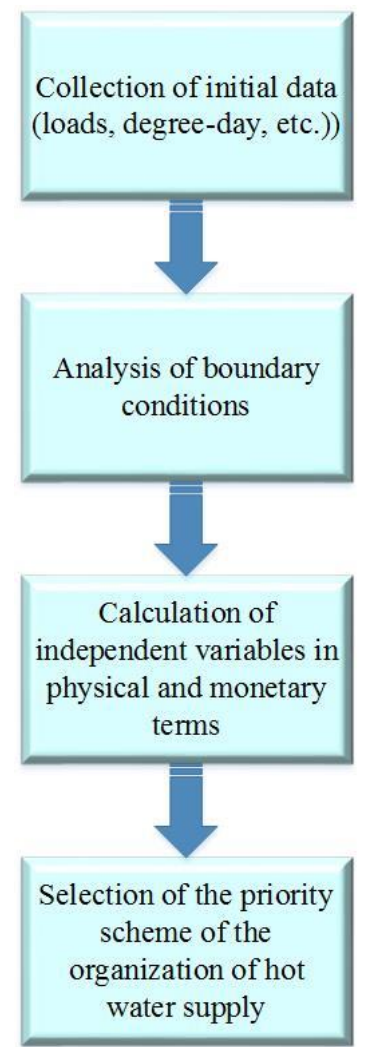

Fig. 2. The basic scheme of selection of the optimal scheme of HWS.

\section{The development of the selection program the optimum scheme of the HWS}

The main indicator for choosing the scenario of transition to a closed system, as noted in Fig. 1, is the cash costs for the life cycle of the newly introduced or reconstructed objects of the heat supply system. However, due to inflation, changes in market prices for equipment and other factors affecting the final cost of the project, the use of accurate quantitative indicators to select the optimal solution is difficult. For this reason, the basis for the developed methodology was the analysis of many relevant feasibility studies for various projects with the choice of qualitative weights for each of the criteria.

Based on the obtained information formed a pyramid of indicators influencing the main indicator for the selection of scenarios for the transition to a closed system - the operating costs of the heating system in the 25 years of its use. The pyramid is shown schematically in Fig. 3. The factors influencing all 7 of the indicators considered earlier (Fig. 1).

Based on Fig. 3 capital expenditure includes 2 factors, while annual expenditure includes 3 factors. For fig. 4 - 6 the interface of the program of the choice of the optimum scheme of transition to the closed HWS system with calculation of weight coefficients is presented. At the same time, the weight coefficient equal to 1 approximately corresponds to the costs equal to 100 million rubles.

\section{Conclusion}

According to the results of the analysis, the following conclusions can be drawn:

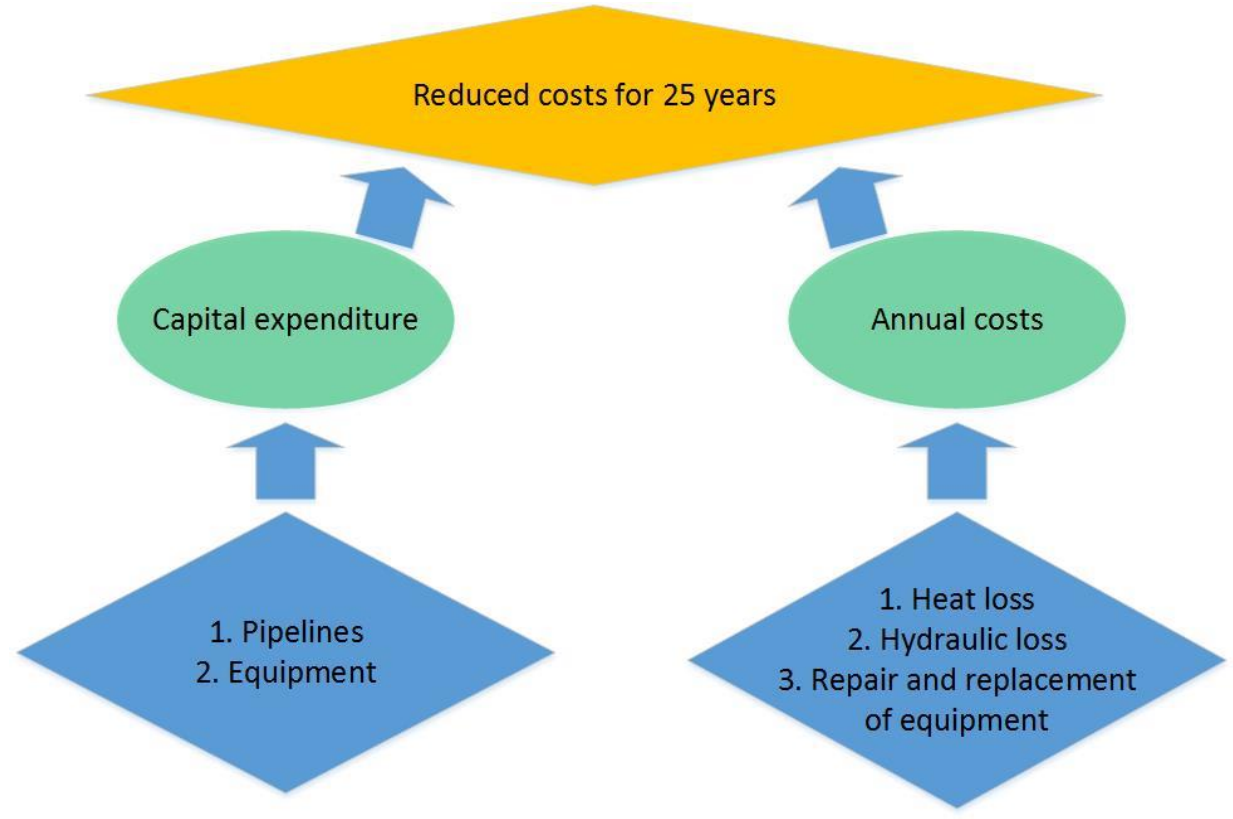

Fig. 3. Cost pyramid for 25 years of operation. 


\begin{tabular}{|c|c|c|c|}
\hline \multicolumn{2}{|l|}{ City: } & \multicolumn{2}{|c|}{ Nefteyugansk } \\
\hline \multicolumn{2}{|l|}{ Thermal load, Gcal/h: } & \multicolumn{2}{|c|}{347,3} \\
\hline \multicolumn{2}{|l|}{ Load heating } & \multicolumn{2}{|c|}{313,7} \\
\hline \multicolumn{2}{|l|}{ Load of hot water supply } & \multicolumn{2}{|c|}{33,6} \\
\hline \multicolumn{2}{|c|}{ heat consumption, Gcal/year } & \multicolumn{2}{|c|}{636047} \\
\hline \multicolumn{2}{|l|}{ number of subscribers } & \multicolumn{2}{|c|}{1326} \\
\hline \multicolumn{2}{|c|}{ Average network diameter, $\mathrm{mm}$} & \multicolumn{2}{|c|}{80} \\
\hline \multicolumn{4}{|c|}{ Analysis of boundary conditions: } \\
\hline $\begin{array}{l}\text { Availability of space for } \\
\text { equipment }\end{array}$ & Нет & Да & \\
\hline Availability of cutting & Нет & Да & \\
\hline \multicolumn{4}{|c|}{ The input independent variables: } \\
\hline \multicolumn{2}{|c|}{ degree-day of the heating period } & & 7684,3 \\
\hline \multicolumn{2}{|c|}{ Length of network for IHP, km } & & 155,3 \\
\hline \multicolumn{2}{|c|}{ Electricity tariff, RUB / kWh } & & 6 \\
\hline \multicolumn{2}{|c|}{ Tariff for thermal energy, RUB / Gcal } & & 1723,7 \\
\hline Type of soil (1 - 1,14 dry & & & 1,14 \\
\hline
\end{tabular}

Fig. 4. Input of initial data into the program.

\begin{tabular}{c|c|c|c|c|}
\hline $\begin{array}{c}\text { diameter, } \\
\text { mm }\end{array}$ & $\begin{array}{c}\text { Dry soil in the cost of installation } \\
\text { dump }\end{array}$ & Dry soil with removal & Wet soil in the dump & Wet soil removal \\
\hline 80 & 16225,7 & 17355,48 & 20801,72 & 22293,53 \\
\hline 100 & 19586,28 & 20833,91 & 24169,26 & 25782,91 \\
\hline 125 & 20981,97 & 22167,25 & 25508,4 & 27116,25 \\
\hline 150 & 22969,73 & 24211,56 & 27553,05 & 29160,9 \\
\hline 200 & 26883,82 & 28418,26 & 31470,69 & 33423,71 \\
\hline 250 & 33121,31 & 35089,88 & 37833,5 & 40132,87 \\
\hline 300 & 36037,88 & 37683,05 & 40680,13 & 42735,89 \\
\hline 350 & 42216,64 & 44354,67 & 46910,79 & 49507,08 \\
\hline 400 & 48161,93 & 50299,96 & 52823,73 & 55454,14 \\
\hline 450 & 54361,8 & 56618,46 & 59029,92 & 61783,43 \\
\hline 500 & 59855,17 & 62111,84 & 64493,78 & 67276,8 \\
\hline & & \multicolumn{4}{|c|}{ Ratio of wet and dry soils } & 1,14 \\
\hline
\end{tabular}

Fig. 5. Interim calculations.

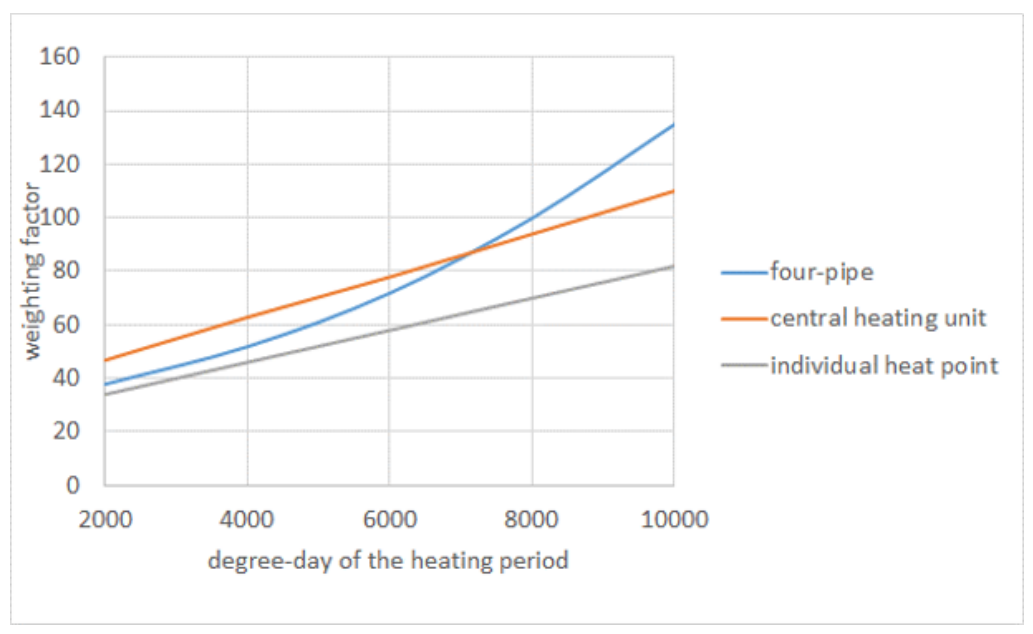

Fig. 6. Calculation results in graphical form.

- The main indicator for choosing the option of transition to a closed system is the cost of 25 years of operation of the newly introduced or reconstructed heat supply system. However, due to inflation, changes in market prices for equipment and other factors affecting the final cost of the project, the use of accurate quantitative indicators to select the optimal solution is difficult.

- It was found that the implementation of a closed system hot water material characteristics of the pipelines increases as follows: $100 \%$ for four-pipe line (in the 
translation of the closed circuit hot water through a fourpipe scheme, it is required to lay $100 \%$ of the material characteristics of the piping hot water from source to consumers); $70 \%$ for a pipeline with a CHU (when transferring to a closed circuit hot water through the $\mathrm{CHU}$, is required to pave about $70 \%$ of the material characteristics of the piping hot water from $\mathrm{CHU}$ to consumers); $0 \%$ for the pipeline with IHP (backbone pipeline for hot water is not laid).

- The most dramatic increase in heat loss is observed for the four-pipe system. So for DDHP value equal to 9000 , is notable the equality of size of thermal losses for four-pipe heating system and system and IHP.

- DDHP is the most important indicator when choosing a reconstruction option, since heat losses are about $55 \%$ of all costs.

- The developed method has confirmed its applicability in comparison with the detailed feasibility study, as the use of accurate quantitative indicators to select the optimal solution is difficult.

\section{References}

1. A.N. Kolesnikov, M.A. Mitin, Analysis of execution of the Federal law 416-FZ on transition to closed DHW systems, New equipment and technologies, 2/2017, 84-92 (2017)

2. V.S. Puzakov, Analysis of the development of heat supply schemes in the Russian Federation, Water supply and sanitary engineering, 7, 4-13 (2015)

3. I.M. Strenadko, R.Yu. Rozhkov, A.V. Kiyski, On problems of open thermal supply grids, Thermal supply news, 1, 34-38 (2013)

4. D.V. Zhukov, S.V. Chicherin, Some results of hydraulic tests on the main thermal networks of the city of Omsk, Problems of energy, 19(1-2), 15-22 (2017)

5. S.A. Tikhomirov, A.I. Vasilenko, Problems of transition to closed thermal supply grids, Don engineering bulletin, 4(27) (2013)

6. I.V. Postnikov, V.A. Stennikov, Providing parametric reliability of heat supply systems, Problems of energy, 19(3-4), 20-30 (2017)

7. F.N. Gazizov, N.T. Amosov, Prospective and problems of broad introduction of the closed thermal supply grids in settlements of Russian Federation, Energy saving - theory and practice: in proceedings of Ninth International school seminar of young scientists and specialists (2018) 